\title{
Perception of Discharge Planning and Quality of Life among Patients with Coronary Artery Disease
}

\section{Norfidah Mohamad, Zamzaliza Abdul Mulud, Iffah Jamaludin, Syarifah Nursyazwani Syed Omar}

\author{
Centre for Nursing Studies, Faculty of Health Sciences, \\ Universiti Teknologi MARA, Puncak Alam Campus, Selangor, Malaysia \\ norfidah@uitm.edu.my, zamzaliza@uitm.edu.my, iffahjamaludin@gmail.com, syarifahnursyazwani@gmail.com \\ Tel: +60332584356
}

\begin{abstract}
Comprehensive discharge planning may enhance dimensions of the quality of life (QoL) in patients with coronary artery disease (CAD). Hence, the purpose of this study is to identify the correlation between perception of discharge planning and QoL among patients with CAD. A cross-sectional study was conducted using a self-administered questionnaire to 152 patients with $C A D$. The results from this study proved that majority of patients with $C A D$ had a high level of $Q o L$ in the emotional domain (rho $=-0.015, p=0.857$ ) but low in the physical domain (rho $=0.066, p=0.422$ ) and social domain (rho $=0.008, p=0.920)$.
\end{abstract}

Keywords: discharge planning; quality of life; coronary artery disease

eISSN: 2398-4287@ 2020. The Authors. Published for AMER ABRA cE-Bs by e-International Publishing House, Ltd., UK. This is an open access article under the CC BYNC-ND license (http://creativecommons.org/licenses/by-nc-nd/4.0/). Peer-review under responsibility of AMER (Association of Malaysian Environment-Behaviour Researchers), ABRA (Association of Behavioural Researchers on Asians) and cE-Bs (Centre for Environment-Behaviour Studies), Faculty of Architecture, Planning \& Surveying, Universiti Teknologi MARA, Malaysia.

DOI: https://doi.org/10.21834/ebpj.v5i14.2185

\subsection{Introduction}

Coronary artery disease (CAD) is a leading cause of morbidity and mortality worldwide. It is related to significant physical, emotional and social aftermath (Cepeda-Valery et al., 2011) and CAD accounted for the most common cause of death in Malaysia, which is 98.9 deaths per 100,000 populations. The National Cardiovascular Disease archive showed that Malaysians at a younger age having CAD compared to other advanced countries. CAD accounted for about $7.68 \%$ of total admissions and approximately $21.70 \%$ of mortality in government hospitals in the year 2017 and are the primary cause of death in Malaysia. By 2020, CAD causes more deaths and disability and incurs higher economic costs than any other illness in the developed world (Antman et al., 2018). The impact of a coronary event risked a person's life. It may cause disability, rising the attention for proper discharge planning and assessment of the quality of life (QoL) among CAD patients.

QoL is a state of well-being in which consist of the ability to perform everyday activities which reflects the psychological, social wellbeing and physical of an individual. In this study, QoL referred to a person's perceived physical and mental health over time (Karimi \& Brazier, 2016). Bilbao et al., (2016), identify the level of QoL using the Minnesota Living with Heart Failure Questionnaire (MLHFQ) among patients with HF and found that patients with HF need special attention regarding the risk of worse QOL.

Discharge planning can enhance dimensions of QoL in patients with CAD, which includes treatments related awareness, activities schedule, nutritional diets advice, stress management and visiting patients (Mazloum et al., 2016). Patients with CAD, most are discharged with unresolved medical issues, which required outpatient's follow-up to maintain their health and safety which includes daily prescriptions, lifestyle modifications, and complex treatment regimens, thus coping is vital for CAD management (Schulman-green et al., 2012). Therefore, discharge planning is essential for their management as it can encourage their recovery after discharge. Aim of

eISSN: 2398-4287@ 2020. The Authors. Published for AMER ABRA cE-Bs by e-International Publishing House, Ltd., UK. This is an open access article under the CC BYNC-ND license (http://creativecommons.org/licenses/by-nc-nd/4.0/). Peer-review under responsibility of AMER (Association of Malaysian Environment-Behaviour Researchers), ABRA (Association of Behavioural Researchers on Asians) and cE-Bs (Centre for Environment-Behaviour Studies), Faculty of Architecture, Planning \& Surveying, Universiti Teknologi MARA, Malaysia.

DOI: https://doi.org/10.21834/ebpj.v5i14.2185 
this present study was to identify the perception of discharge planning and the level of QoL and its relationship with demographic characteristics.

\subsection{Literature review}

The Association of Discharge Planning Coordinators of Ontario (ADPCO) in 1997 defined discharge planning is an interdisciplinary approach to continuity of care; it is a process that includes identification, assessment, goal setting, planning, implementation, coordination, and evaluation (Lin et al., 2012). The discharge planning process, program or services is much likely related to the continuity of care for patients, especially after discharge. In the previous study, it reported that continuity is essential to the medical community as there was a positive consistency of the relationship between continuity of care (Cepeda-Valery et al., 2011).

A review of the literature by Lin et al. (2012) indicates that a hospital often discharges patients with insufficient planning, poor instruction, inadequate information, lack of coordination among members of the healthcare team, and poor communication between hospitals and community. In the first place, discharge planning services were initiated as an attempt to improve the quality of patient care, particularly for the aged and those with long-term health care problems, it somehow affects the patient's QoL. Hence discharge planning was developed and has always been viewed as a major way to improve the quality of care and solve the post-discharge care problems.

QoL is progressively used to evaluate the health status of patients and the broad public as well as the outcome of healthcare interventions. It also indicates a personal perception of life in different aspects, which is in line with the patient's standards and expectation (Saeidi et al., 2013). This is important for people with CAD with angina symptoms, heart insufficiency, limited activities and physical disabilities can affect patients' QoL. It is remarkable as in a recent study by Bayliss et al., (2017) reported improving the QoL half of the patients preferred to undergo the treatment even though it could shorten their life expectancy and ensure better compliance with therapeutic requirements. QoL criteria such as the rate of survival, mortality, and illness replaced with an assessment of the QoL to determine the results of the health care of the patients (Spiraki et al., 2008).

Another study by Shojaee et al. (2013) proved that there is a significant correlation between perception of discharge planning and QoL as proper discharge planning causes a considerable decrease in the level of hospital and clinical readmissions as well as showing their QoL was improving. Related to a study in 2007 by Anderson et al. that reported patient's education during discharge and follow-up after discharge causes fewer readmissions, thus also improving patient's QoL. Other than that, statistics by Mazloum et al., (2016) shows that over one hundred thousand CAD patients are rehospitalized in medical centres due to relapse of the disease. The main reasons for rehospitalization are ineffective follow-up, patient incompliance and discharging without a plan. Patients are frequently left ad hoc at discharge, as many do not fully comprehend their discharge medications (Jack et al., 2009).

Moreover, with today's shorter lengths of stay and higher awareness come across, there is not enough time to provide the patient with needed education and information. Consequently, the information given in such a rush, last-minute method does not tally with patients' needs and end up will affect a patient's life after discharge. Such studies are needed to determine the attainability and efficacy of such methods to reduce CAD.

\subsection{Methodology}

\subsection{Sample}

A cross-sectional study was used in this research. The study was conducted at UiTM Medical Specialist Centre, Sungai Buloh. Purposive sampling method was chosen for this research with a sample size of 152. The samples were selected based on inclusion criteria of this study: (1) patients need to be diagnosed with CAD for at least five years and above; (2) patients who are currently admitted in UiTM Medical Specialist Centre for more than seven days; (3) patients who have been discharged about 6 to 12 months from the centre. Meanwhile, the exclusion criteria of this study were (1) patients that have undergone open-heart surgery such as CABG.

\subsection{Instruments}

A self-administered questionnaire was adopted by previous research which consists of three sections. In Section A, the questions are on the demographic characteristics of respondents. Section B comprises of Patient Continuity of Care Questionnaire (PCCQ), consists of 25 closed-ended items using a 5-point Likert-Type scale from scale 1 "strongly disagree" to scale 5 "strongly agree" to assess the perception of discharge planning. Scoring of PCCQ as the sum-up of the possible range is 27-135 with categorization into three levels as low (27-62), moderate (63-99) and good (100-135). Section C is 27 closed-ended questions using The MacNew Heart Disease Health-Related QoL questionnaire to evaluate on how heart diseases affect patients' feelings and conditions daily. It is a 7-point Likerttype scale from scale 1 "all of the time" which indicate low QoL to scale 7 "none of the time" that indicate high QoL among patients with heart disease. The global domain scores of MacNew questionnaires were considered by median and interquartile range as 4.1(3.6-4.6) for low QoL, 5.6 (5.3-5.9) for moderate QoL and 6.5 (6.2-6.7) for high QoL.

\subsection{Data collection methods}

The data was collected in UiTM Medical Specialist Centre, Sg. Buloh through identifying participants that suit the inclusion and exclusion criteria. The participants were then explained about the study information and asked whether they have the time and want to participate 
or not. The ones that have agreed with the terms of participating in the study, and they were asked to sign their consent before answering the questionnaire to ensure the confidentiality of all the information gathered.

\subsection{Statistical analysis}

Complete questionnaires were analyzed by using IBM Statistical Package for the Social Sciences (SPSS) for windows version 21.0. The descriptive analysis method is used to test and analyze the level of perception of discharge planning and QoL. Spearman's coefficient of correlation is used to determine the relationship between the level of perception of discharge planning and QoL with normality test by Kolmogorov-Smirnov.

\subsection{Findings}

\subsection{Demographic data}

The demographic data for this study is shown in Table 1, including age, gender, education level, marital status and family history of heart disease. A total of 152 participants was involved in this study. According to the results, nineteen (12.5\%) of respondents between $30-39$ years old, forty-seven (30.9\%) of respondents between 40 - 49 years old, fifty-five $(36.2 \%)$ of the respondents between the age of $50-59$, thirty-one $(20.4 \%$ ) of respondents between $60-69$ years of age. The number of respondents participating in this study was dominated by males, which consist of 142 respondents $(93.4 \%)$. The other ten respondents $(6.6 \%)$ were females. More than half of the respondents engaged in this study were high school graduates with a total of 92 respondents $(60.5 \%)$, followed by 40 respondents $(26.3 \%)$ further their education in universities, and 20 respondents $(13.2 \%)$ studied until primary level. Majority of the respondents participated in this study were married, which comprise of 133 respondents (87.5\%) while the remaining 19 respondents $(12.5 \%)$ were recorded not married. Other than that, almost three-quarters of participants contributed to this study, which was 123 participants $(80.9 \%)$ stated that they do not have family members with a history of heart disease. Whereas the other $19.1 \%$, which consist of 29 respondents reported that they have a family with a history of heart disease.

Table 1. Demographic Characteristics of Patients with $\operatorname{CAD}(n=152)$

\begin{tabular}{lcc}
\hline Characteristics & Frequency $(\mathrm{n})$ & Percentage $(\%)$ \\
\hline Age & 19 & 12.5 \\
$30-39$ & 47 & 30.9 \\
$40-49$ & 55 & 36.2 \\
$50-59$ & 31 & 20.4 \\
$60-69$ & & \\
Gender & 142 & 93.4 \\
Male & 10 & 6.6 \\
Female & & \\
Education level & 20 & 13.2 \\
Primary school & 92 & 60.5 \\
High school & 49 & 26.3 \\
University & & \\
Marital status & & 12.5 \\
Not married & 19 & 87.5 \\
Married & 133 & \\
Family history of heart disease & & 80.9 \\
No & 123 & 19.1 \\
Yes & 291 & \\
\hline
\end{tabular}

4.2 Level of Perception of Discharge Planning and Quality of Life

Results from descriptive statistics show patients had a high level of perception of discharge planning and having a moderate level of QoL in an emotional domain $(n=92,60.5 \%)$ and low level of QoL in the physical and social domain $(n=124,81.6 \%),(n=92,60.5 \%)$ respectively.

\subsection{Correlation between Level of Perception of Discharge Planning and Quality of Life}

Table 2 shows there is no correlation between the level of perception of discharge planning and the level of QoL which was, emotional (rho $=-0.015, p=0.857)$, physical (rho $=0.066, p=0.422)$ and social (rho $=0.008, p=0.920)$.

Table 2. Correlation between Level of Perception of Discharge Planning and QoL among Patients with CAD

\begin{tabular}{lcl}
\hline QoL & Perception of discharge planning & \\
& Correlation coefficient & P-value \\
\hline Emotional QoL & -0.015 & 0.857 \\
Physical QoL & 0.066 & 0.422
\end{tabular}




\begin{tabular}{lll}
\hline Social QoL & 0.008 & 0.920
\end{tabular}

\subsection{Relationship between Level of Perception of Discharge Planning and Demographic Characteristic}

Table 3 displays the relationship between the level of perception of discharge planning and demographic data. Level of perception of discharge and age groups showed a statistically significant result with $F(3,148)=5.163, p=0.002$. Kruskal Wallis test was used to measure the relationship between the level of perception of discharge planning with gender and level of education. The median \pm IQR for the male is $114.00 \pm 10.0$ and female is $116.00 \pm 4.00$. In the Kruskal Wallis test, the analysis was significant, $F(1,150)=5.855$, $p=0.018$. In terms of the level of education and perception of discharge planning, the result was not significant, $F(2,149)=2.347$, $p=0.135$. One-way ANOVA test was used to test the relationship between the level of perception of discharge planning with marital status, and family history of heart disease and the results found that there was no significant relationship $F(1,150)=0.576, p=0.449$.

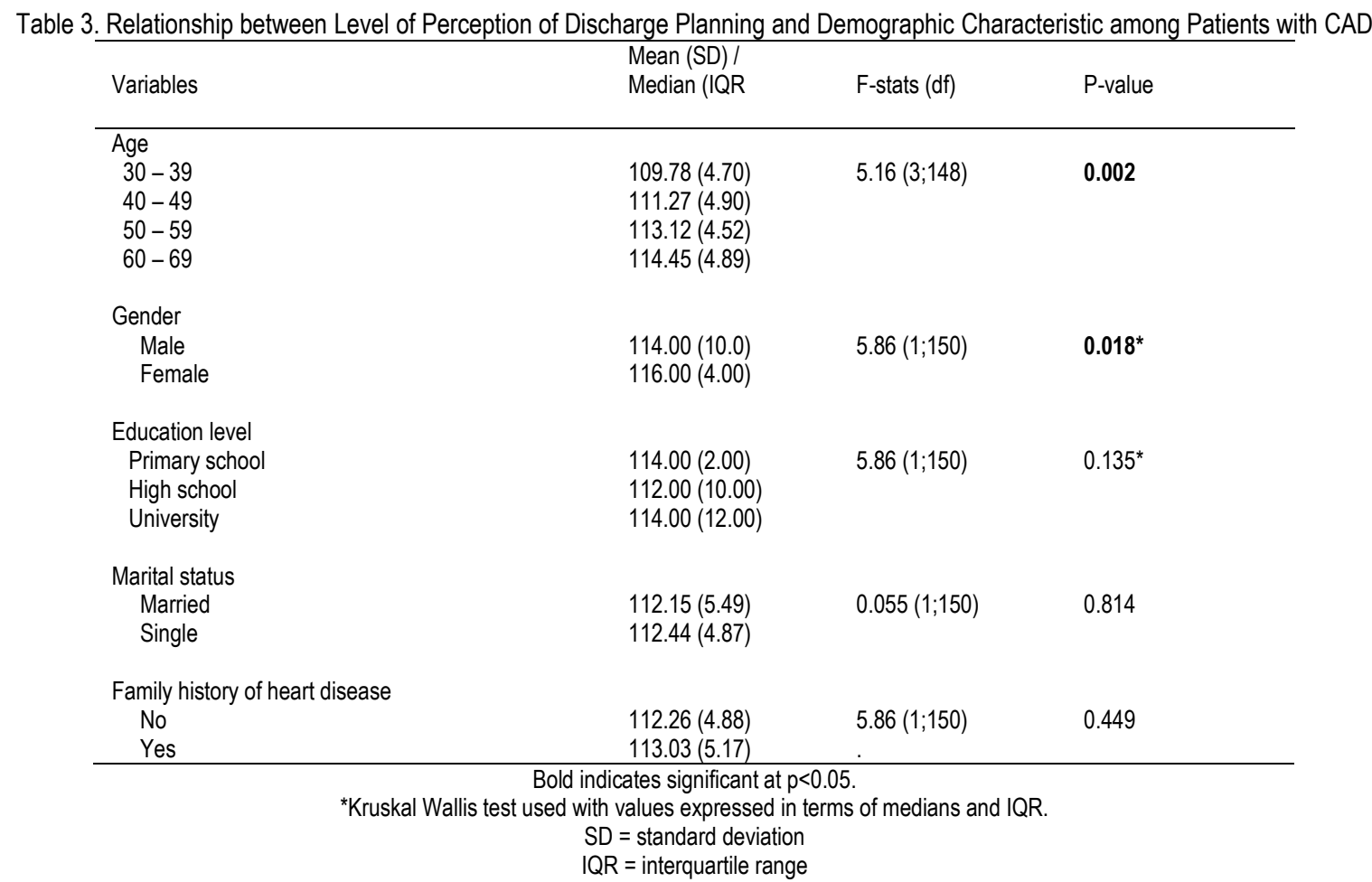

\subsection{Relationship between Level of Quality of Life and Demographic Data among Patients with CAD}

The Chi-square test for the relationship between the level of emotional, physical and social QoL with age groups showed a statistically significant result, with $X^{2}(3)=9.675, p=0.220, X^{2}(3)=17.778, p=<0.001$, and $X^{2}(6)=21.191, p=0.002$ respectively. Hence, there was a significant relationship between QoL, except emotional with age groups among patients with CAD. Test result between emotional and social subscale of QoL with the family history of heart disease found that there was statistically significant with $X^{2}(1)=10.174, p=0.001$ and $X^{2}(2)=13.738, p=0.001$ for both subscales. Finally, there was no significant relationship between the level of QoL with gender, level of education, marital status and having a family history of heart disease among patients with CAD with $p>0.05$.

\subsection{Discussion}

\subsection{Level of Perception of Discharge Planning and Quality of Life}

The findings of this study indicated that respondents with CAD had a high level of perception of discharge planning. These findings were supported by a previous study by Cepeda-Valery et al., (2011) in which the respondents indicated high levels ( $\mathrm{n}=57,54 \%$ ) of satisfaction with the perception of discharge planning in general as most respondents felt that they were adequately prepared to be discharged. They trusted that different providers had good communications between each other to ensure quality discharge planning. Approximately, a recent study by Bayliss et al., (2017) showed most of the respondents had moderate levels of care coordination and quality of discharge teaching. Apart from that, Aller et al. (2013) also found the level of perception of discharge planning was perceived as high by the respondents. On the other hand, over $50 \%$ of the respondents recorded that they did not feel they or their caregiver had been informed with sufficient discharge planning resources that help ensure continuous care (Hadjistavropoulos et al., 2008).

This study revealed that both physical and social QoL were recorded as low. This showed that most respondents were cautious and scared of physical activities as they had the impression of doing physical activities can aggravate their condition. Patients with CAD often stayed away from social events as they were not confident of their health. However, the majority recorded good emotional QoL, 
with none recorded in low QoL. This study found that the respondents scored high in psychological QoL as they were aware and knowledgeable regarding their disease process. These findings were supported by a recent study by Vecchis \& Ariano in 2016 in which the majority of the respondents scored low QoL in all three aspects. Similar to a study done in Netherlands in 2010, in which most respondents scored low QoL while only a minority scored high QoL in all elements (Schenkeveld et al., 2010). Previous studies revealed low QoL scored in the majority patients with CAD (Spiraki et al., 2008; Davis et al., 2017) they reported that respondents scored low QoL as their QoL were influenced by other chronic diseases that the patients have.

\subsection{Correlation between Level of Perception of Discharge Planning and Quality of Life}

In this study, there was no correlation between the level of perception of discharge planning and all three subscales of QoL. This result supported by the study done by Lin et al. (2009) in Taiwan. In Lin's research, discharge planning proved as having little effect on the different aspects of QoL due to no close emotional touch with the patients and their families. Similarly, a recent study in Colorado found a lack of association between discharge planning and QoL (Bayliss et al., 2017). However, this result findings contradict with the correlation between perception of discharge planning and QoL in Iran (Mazloum et al., 2016). The researcher found out that discharge planning was significantly effective on each one of the aspects of QoL for patients with CAD. The result was consistent with a study by (Azadi \& Mohammadi, 2007; Spiraki et al., 2008), showed a significant improvement between discharge planning and all aspects of QoL. Another study proved that there is a significant correlation between perception of discharge planning and QoL as proper discharge planning cause a significant decrease in the level of hospital stay and clinical readmissions as well as showing their QoL was improving (Shojaee et al., 2013).

\subsection{Relationship between Level of Perception of Discharge Planning and Demographic Characteristic}

From the research's finding, there is a significant relationship between the level of perception of discharge planning with two demographic data, which are age groups and gender. However, there is no significant relationship between the level of perception of discharge planning with the other three remaining demographic data, which are level of education, marital status and family history of heart disease. A study in Iran showed that there was no significant relationship between discharge planning with gender and marriage status (Shojaee et al., 2013). Similarly, there was no significant relationship between gender and patients' discharge information needs, but the study found that female needs more discharge information compared to male. A study in Norway found that there was no significant relationship between discharge planning and age and level of education; however, they found that there is a significant relationship between discharge planning and gender (Valaker, et al., 2019). Dispute to a previous study conducted in Universiti Kebangsaan Malaysia Medical Centre (UKMMC) in Kuala Lumpur, the results showed only race significant relationship with patients' discharge information needs (Sz, et al., 2018). There was also a relationship between continuity of care and age as they found that the older groups had a higher level of perceptions of discharge planning than the younger groups (Aller, et al., 2013).

\subsection{Relationship between Level of Quality of Life and Demographic Characteristic}

There is a significant relationship between $\mathrm{QoL}$ and age groups among patients with CAD. There is no significant relationship between QoL and two demographic data, which were gender and level of education among patients with CAD. Other than that, results indicate that there is no significant relationship between emotional QoL and marital status, but there is a significant positive relationship between physical and social subscales of QoL with marital status among patients with CAD. Similar to a study conducted in China showed that older patients with CAD have significant poorer QoL, especially if their health deteriorating (Chen, et al., 2018). A study in the Czech Republic showed that there was no significant relationship between QoL and family history of heart disease as the groups did not differ statistically (Pospíchal et al., 2018). However, a study in Thailand and Canada found a significant relationship between QoL with gender and age as well as a relationship between gender and QoL as women reported a significant lower QoL compared to men (Silavanich et al., 2019; Norris et al., 2010).

\subsection{Conclusion \& recommendations}

The perception of discharge planning among patients with CAD was high, and the level of QoL high in emotional aspects, and a low level of QoL in physical and social aspects. The findings from this study would create awareness to the community as well as the health providers as it may reveal the overall perception of discharge planning and QoL among patients with CAD. On the whole, since the general health of respondents of this study were influenced by healthcare providers, it is important to ensure that the patients obtain sufficient information that can facilitate their life quality. There were a number of limitations to this study. The limitations were the small sample size and the limitation of the geographical area. This study focused on the respondents in one centre only. Future research should identify the factor that can influence the perception of discharge planning and QoL, to determine the importance of both variables, especially in patients with chronic diseases such as CAD. The second recommendation would be to use a larger sample size and include other settings such as other hospitals because different hospitals might have different protocols of discharge planning. Thus, to prove the correlation between perception of discharge planning and quality of life, it would be better to include other hospitals in future studies.

\section{Acknowledgements}

The authors wish to acknowledge Centre for Nursing Studies, Faculty of Health Sciences UiTM, Research Ethics Committee UiTM Shah Alam, UiTM Specialist Medical Centre, Sungai Buloh for their contribution in this study. 


\section{References}

Aller, M. B., Vargas, I., Waibel, S., Coderch, J., Sánchez-Pérez, I., Colomés, L., ... Vázquez, M. L. (2013). A comprehensive analysis of patients' perceptions of continuity of care and their associated factors. International Journal for Quality in Health Care, 25(3), 291-299. https://doi.org/10.1093/intqhc/mzt010

Antman, E., Selwyn, A., Braunwald, E., \& Lascalzo, J. (2018). Ischemic Heart Disease. In Harrisons's Principles of Internal Medicine (17th ed). New York: McGraw-Hill.

Azadi, F., \& Mohammadi, I. (2007). Effects of partnership care model on quality of life of coronary artery disease patients. Iranian Journal of Nursing.

Bayliss, E. A., Ellis, J. L., Shoup, J. A., McQuillan, D. B., Steiner, J. F., \& Zeng, C. (2017). Association between Continuity of Care and Health-Related Quality of Life. The Journal of the American Board of Family Medicine, 30(2), 205-212. https://doi.org/10.3122/jabfm.2017.02.160225

Bilbao, A., Escobar, A., García-Perez, L., Navarro, G., \& Quirós, R. (2016). The Minnesota living with heart failure questionnaire: Comparison of different factor structures. Health and Quality of Life Outcomes, 14(1). https://doi.org/10.1186/s12955-016-0425-7

Cepeda-Valery, B., Cheong, A. P., Lee, A., \& Yan, B. P. (2011). Measuring health-related quality of life in coronary heart disease: The importance of feeling well. International Journal of Cardiology, 149(1), 4-9. https://doi.org/10.1016/j.jicard.2010.09.048

Chen, Z., Geng, J., Wang, M., Hu, L., Ghisi, G. L. de M., \& Yu, H. (2018). The Chinese version of the coronary artery disease education questionnaire-ii (CADEQ-II): Translation and validation. Patient Preference and Adherence, 12, 1587-1596. https://doi.org/10.2147/PPA.S176639

Davis, J., Olsen, M., Bommarito, K., LaRue, S., Saeed, M., Rich, M., \& Vader, J. (2017). All-Payer Analysis of Heart Failure Hospitalization 30-Day Readmission: Comorbidities Matter. American Journal of Medicine, 130(1), 93.e9-93.e28. https://doi.org/10.1016/j.amjmed.2016.07.030

Hadjistavropoulos, H., Biem, H., Sharpe, D., Bourgault-Fagnou, M., \& Janzen, J. (2008). Patient perceptions of hospital discharge: Reliability and validity of a patient continuity of care questionnaire. International Journal for Quality in Health Care, 20(5), 314-323. https://doi.org/10.1093/intqhc/mzn030

Jack, B. W., Chetty, V. K., Anthony, D., Greenwald, J. L., \& Sanchez, G. M. (2009). Annals of Internal Medicine A Reengineered Hospital Discharge Program to Decrease Rehospitalization: A randomized trial. Annals of Internal Medicine, 150(25), 178-187.

Karimi, M., \& Brazier, J. (2016). Health-Related Quality of Life, and Quality of Life: What is the Difference? PharmacoEconomics, 34(7), 645-649. https://doi.org/10.1007/s40273-016-0389-9

Lin, P. C., Wang, C. H., Chen, C. S., Liao, L. P., Kao, S. F., \& Wu, H. F. (2009). To evaluate the effectiveness of a discharge-planning programme for hip fracture patients. Journal of Clinical Nursing, 18(11), 1632-1639. https://doi.org/10.1111/j.1365-2702.2008.02695.x

Mazloum, S., Heidari-Gorji, M., Bidgoli-Gholkhatmi, M., \& Agayei, N. (2016). Effectiveness of discharge-planning on physical quality of life of patients with ischemic heart disease. International Journal of Applied and Basic Medical Research, 6(2), 129. https://doi.org/10.4103/2229-516x.179018

Ministry of Health Malaysia. (2017). Ministry of Health, Malaysia: Annual Report 2017.

Norris, C. M., Murray, J. W., Triplett, L. S., \& Hegadoren, K. M. (2010). Gender roles in persistent sex differences in health-related quality-of-life outcomes of patients with coronary artery disease. Gender Medicine, 7(4), 330-339. https://doi.org/10.1016/j.genm.2010.07.005

Pospíchal, J., Vojtíšek, P., Bobák, M., \& Matějka, J. (2018). A comparison of health-related quality of life and disease severity in patients with stable coronary artery disease. Kontakt, 20(3), e237-e243. https://doi.org/10.1016/j.kontakt.2018.04.001

Saeidi, M., Mostafavi, S., Heidari, H., \& Masoudi, S. (2013). Efectos de un programa integral de rehabilitación cardiaca en la calidad de vida en pacientes con enfermedad arterial coronaria, 9(3), 179-185

Schenkeveld, L., Pedersen, S. S., van Nierop, J. W. I., Lenzen, M. J., de Jaegere, P. P. T., Serruys, P. W., \& van Domburg, R. T. (2010). Health-related quality of life and long-term mortality in patients treated with percutaneous coronary intervention. American Heart Journal, 159(3), 471-476. https://doi.org/10.1016/j.ahj.2009.12.012

Schulman-green, D., Jaser, S., Martin, F., Alonzo, A., Grey, M., Mccorkle, R., ... Whittemore, R. (2012). Processes of Self-Management in Chronic Illness, $136-144$. https://doi.org/10.1111/j.1547-5069.2012.01444.x

Shojaee, A., Nehrir, B., Naderi, N., \& Zareaeyan, A. (2013). Assessment of the effect of patient's education and telephone follow up by nurse on readmissions of the patients with heart failure. Journal of Critical Care Nursing, 6(1), 29-38.

Spiraki, C., Kaitelidou, D., Papakonstantinou, V., Prezerakos, P., \& Maniadakis, N. (2008). Health-related quality of life measurement in patients admitted with coronary heart disease and heart failure to a cardiology department of a secondary urban hospital in Greece. Hellenic Journal of Cardiology : HJC = Hellēnikē Kardiologikē Epitheōrēsē, 49(4), 241-247.

Sz, H., Hassan, N. H., Sin, C. S., Hwa, N. C., Siew, S., \& Maskon, O. Bin. (2018). Patients ' Discharge Information Needs Regarding Acute Coronary Syndrome in Teaching Hospital, 1(1), 49-58.

Valaker, I., Fridlund, B., Wentzel-Larsen, T., Hadjistavropoulos, H., Nordrehaug, J. E., Rotevatn, S., ... Norekvål, T. M. (2019). Adaptation and psychometric properties of the Norwegian version of the heart continuity of care questionnaire (HCCQ). BMC Medical Research Methodology, 19(1), 1-16. https://doi.org/10.1186/s12874-0190706-z

Vecchis, R. De, \& Ariano, C. (2016). The MacNew Questionnaire: A Tool to Predict Unplanned Rehospitalization after Coronary Revascularization. International Journal of Cardiovascular Sciences, 29(4), 303-313. https://doi.org/10.5935/2359-4802.20160047 